\title{
Solving a contextual problem with the spreadsheet as an environment for algebraic thinking development
}

\author{
Sandra Nobre**十, Nélia Amadot: ANd Susana CarreIRA: \\ ${ }^{\dagger}$ Escola Básica 2,3 Prof. Paula Nogueira and Unidade de Investigação do Instituto de Educação, \\ Universidade de Lisboa and $₫ F C T$ da Universidade do Algarve and Unidade de Investigação do Instituto de \\ Educação, Universidade de Lisboa \\ *Email: sandraggnobre@gmail.com
}

In this article we report and discuss a contextual problem solving task that was proposed to a class of 8th grade (13-14-year-old) students. These students had been developing a reasonable experience in the use of the spreadsheet to model relations within contextual problems and chose to use this tool to solve the mentioned problem, engaging in the process of translating relations between variables and combining them in chained models, while working with fractions, multiples and expressions. We intend to highlight the role of the spreadsheet in students' processes of variable identification and translation of the problem conditions, their numerical approaches to algebraic models and their experimental forms of finding solutions to equations.

\section{Introduction}

The spreadsheet has been considered an educational resource with great potential for the construction of algebraic concepts, including the establishment of functional relationships, representing sequences or procedures of a recursive nature, all significant to be used in solving mathematical problems. Our aim is to understand how the spreadsheet supports the work of 8th grade students in solving a contextual problem, by focusing on their ways of representing the variables and the conditions stated in the problem.

\section{Algebraic thinking}

According to Kieran (2007) algebraic thinking is much more than knowledge of algorithms and techniques. To Zazkis \& Liljedahl (2002) the term algebra encompasses two distinct aspects: algebraic thinking and algebraic symbolism, stressing that the presence of algebraic symbolism should be taken as an indicator in that the absence of algebraic notation should not be judged as an inability to think algebraically. This idea is in the spirit advocated by Radford (2000) whereby students are able to think algebraically even when they do not resort to algebraic symbolism in their written productions. The writing of symbolic numerical relations in school algebra has favoured the use of letters. However, the 
availability of technological tools allows other representations of such relations, as well as new forms of their exploration, which can be seen as algebraic activities of generation and transformation. Thus, it seems appropriate that these different representations of numerical relations, as well as the thinking that goes with it, is included in the field of algebra (Kieran, 1996).

\section{Problem solving with the spreadsheet and the development of algebraic thinking}

The spreadsheet is a powerful tool in mathematical problem solving and particularly in the development of algebraic thinking embedded in problem solving activities as highlighted by several authors (e.g. Dettori et al., 2001; Rojano, 2002; Ainley et al., 2004). One of the gains of connecting algebraic thinking and the use of spreadsheets is the creation of a significant environment to induce students into algebraic language that facilitates the construction of algebraic concepts, especially in what concerns working with functional relations, sequences and recursive procedures. Using the spreadsheet in the context of problem solving emphasizes the need to identify the relevant variables involved and fosters the search for variables that depend on other variables, resulting in composed relations. The definition of intermediate relations, by means of spreadsheet formulas in intermediate columns, meaning the decomposition of more complex relations in chained simpler ones, is a special feature inherent to the use of the spreadsheet that amounts to important results in solving algebraic contextual problems (Carreira, 1992; Haspekian, 2005). Moreover, as noted by Haspekian (2005) a spreadsheet also allows an algebraic organization of apparently arithmetical solutions and this kind of hybridism, where arithmetic and algebra naturally cohabit, becomes an educational option that may help students in moving from arithmetic to algebra (Kieran, 1996). Spreadsheets can act as a bridge between arithmetic and algebra by helping students generalize patterns, develop an understanding of variable, facilitate transformation of algebraic expressions, and provide a space to explore equations (Tabach et al., 2008). In addition spreadsheets allow students to focus on the mathematical reasoning by freeing them from the burden of calculations and algebraic manipulations (Ozgun-Koca, 2000). However as Dettori et al. (2001) have noticed from their research on 13 to 14-year-old students' work with spreadsheets on algebraic problems, 'spreadsheets can start the journey of learning algebra, but do not have the tools to complete it. Being able to write down parts of the relations among the considered objects, but not to synthesize and manipulate the complete relations, is like knowing the words and phrases of a language, but being unable to compose them into complete sentences' (p. 206). What still remains a research issue is to understand the scope of the spreadsheet contribution in going further than just the recognition and manipulation of relations among objects to a broader understanding of the algebraic foundations of the methods for solving algebraic conditions.

\section{Methodology}

This study follows a qualitative and interpretative methodology. The participants are four 8th graders (13-14 years), two of them working as a pair and the other two working individually. The students were given the freedom to choose whether or not to work in groups or individually as was part of the didactical contract in the classroom. In both cases the teacher engaged in dialogue with the students and asked questions whenever necessary to appreciate students' reasoning and approaches. They had previously obtained some experience in solving word problems with a spreadsheet in the classroom, from which they acquired the basics of the spreadsheet functioning. Many of the problems that were explored with this class were selected from an online mathematical problem solving competition 
promoted by the University of Algarve, the Sub14, which addresses students of 7th-8th grades. The possibility of participants sending their answers in different digital formats (including spreadsheet files) was seen as an incitement to engage students in working on contextual word problems with the use of the spreadsheet and an opportunity to develop students' algebraic thinking.

The detailed recording of students' processes was achieved with the use of Camtasia Studio. This software allows the simultaneous collecting of the dialogue of the students and the sequence of the computer screens that show all the actions that were performed on the computer. We were able to analyse the students' conversations while we observed their operations on a spreadsheet. This type of computer protocol is very powerful as it allows the description of the actions in real time on the computer (Weigand \& Weller, 2001).

The given problem entitled The Opening of the Restaurant 'Sombrero Style', presented characteristics that were seen as interesting to be explored with the spreadsheet, namely due to the fact that it may be solved by a numerical approach. To a certain extent it proved to be different from other problems solved by the students in the classroom. One of its features relates to the fact of being placed in the form of a narrative, which makes it pretty close to a real situation, where conditions are steeped in the story thus requiring a very careful reading to identify those that are relevant to solving the problem.

The opening of the restaurant 'Sombrero Style'
The restaurant Sombrero Style was opened yesterday and I
was there having dinner with three friends. The maximum
capacity of customers - said the manager-is 100 people.
Luckily I had booked a table for four, because when I got there several tables
were already full with four people and one table had only three people. While
I was waiting for the employee to take us to our table, I counted the women
and men who were in the restaurant and the number of women was exactly
twice the number of men. What could be the maximum number of people who
were already at the restaurant when I came in?

A possible algebraic approach to the problem is presented in Fig. 1. Solving this problem through a formal algebraic approach, namely using a system of equations such as presented, was beyond the reach of these students.

\section{Results}

Students expressed many difficulties in understanding the problem, particularly in the question about the maximum number of people sat in the restaurant before the group of four people arrived. There

$$
\begin{aligned}
& w \text { - number of women, } m \text { - numberof men, } y \text { - total of persons, } x \text { - numbersof tablesof } 4 \text { persons } \\
& \left\{\begin{array}{l}
w=2 m \\
y=w+m \\
y=4 x+3 \\
0<y \leq 100
\end{array} \quad(\max y)\right.
\end{aligned}
$$

FIG. 1. Possible algebraic approach to the problem. 


\begin{tabular}{|c|c|c|c|c|c|}
\hline Tables of 4 & Peopl & & People & \multicolumn{2}{|c|}{ Total } \\
\hline & 1 & 4 & & 3 & 7 \\
\hline & 2 & 8 & & 3 & 11 \\
\hline & 3 & 12 & & 3 & 15 \\
\hline & 4 & 16 & & 3 & 19 \\
\hline & 20 & 80 & & 3 & 83 \\
\hline & 21 & 84 & & 3 & 87 \\
\hline & 22 & 88 & & 3 & 91 \\
\hline & 23 & 92 & & 3 & 95 \\
\hline & 24 & 96 & & 3 & 99 \\
\hline & 25 & 100 & & 3 & 103 \\
\hline
\end{tabular}

\begin{tabular}{|r|r|r|}
\hline Women & Men & \multicolumn{2}{|c|}{ Total } \\
\hline \hline 2 & 1 & 3 \\
\hline 4 & 2 & 6 \\
\hline 6 & 3 & 9 \\
\hline 8 & 4 & 12 \\
\hline 54 & 27 & 81 \\
\hline 56 & 28 & 84 \\
\hline 58 & 29 & 87 \\
\hline 60 & 30 & 90 \\
\hline 62 & 31 & 93 \\
\hline 64 & 32 & 96 \\
\hline
\end{tabular}

FIG. 2. Print-screen of Mary and Jenny's representation. This figure appears in colour in the online version of Teaching Mathematics and its Applications.

were other obstacles that relate to the simultaneous conditions pertaining to the distribution of persons by tables of 3 and 4 and to the division of clients by gender.

Since these students had already worked with the spreadsheet in other problems and knew some of their potentialities, they largely resorted to this tool over other processes to solve the problem.

Mary and Jenny began by writing the condition on the number of people seated at tables of 4, as shown in the first two columns of Fig. 2. In this process the students identify the variable "number of tables of 4' and in the next column show the number of people sitting at these tables. Jenny enters the column referring to the three people that were sat at one of the tables and calculates the total number of people by using the formula ' $=\mathrm{H} 11+\mathrm{G} 11$ '.

Afterwards they separately represent the condition concerning the separation of clients by gender, as shown in Fig. 2. The shaded row in each of the tables shows that the students sought to identify the solution by comparing the columns of totals in the two tables. The work of these students shows how the spreadsheet has helped them overcome the initial difficulties, in that it enabled them to work separately on the different conditions and afterwards relate the feedback from each one to get the solution. The establishment of relations proved to be an intermediate point that facilitated the expression of all conditions present in the statement.

The following is an analysis of the production of Carol, who like her colleagues Mary and Jenny also organized the two conditions by separating them, as shown in Fig. 3.

The student begins by making the separation of customers by gender. The first column represents the integer values of the total number of people in the restaurant, in descending order, the second is the division by 3 for the calculation of one-third and the third column calculates twice the previous results. In the last three columns another condition of the problem is shown, namely, the distribution of customers by tables of 3 and 4 . The successive multiples of 4 represent the various tables with 4 people and as there was only one table with 3 people, the number 3 is repeated in the column for tables of 3. Comparing the two columns with the totals she found how many people were in the restaurant, that is, 87.

In solving the problem, the student uses the concept of fraction to 'separate' the restaurant customers by gender, as mentioned in her answer '.. as the number of women is exactly twice the number of 


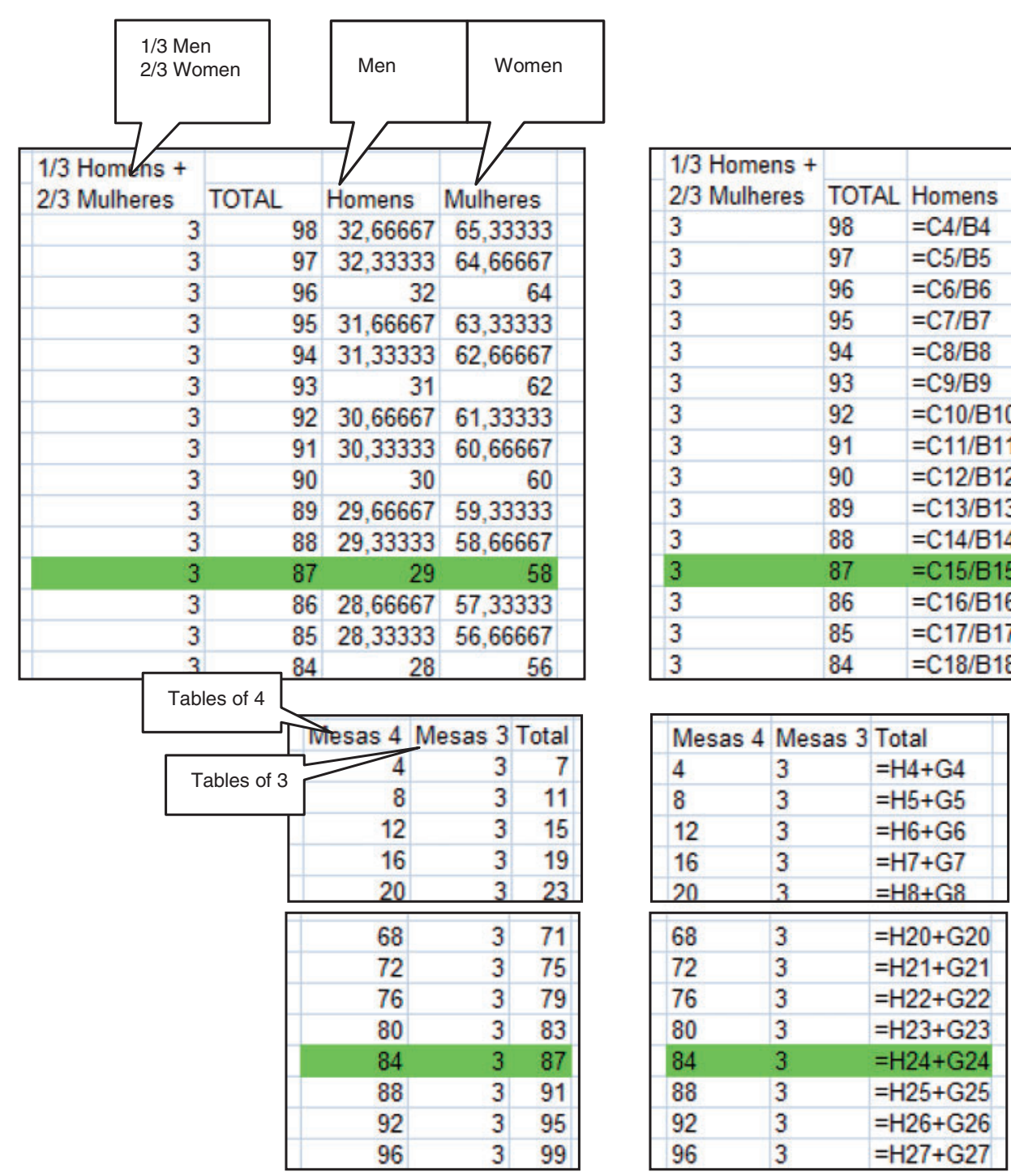

Fig. 3. Print-screen of Carol's representation. This figure appears in colour in the online version of Teaching Mathematics and its Applications.

men, it can be concluded that the sum is represented by three thirds, one third were men and two thirds were women ...'

She also uses the notion of multiples of four to define the number of people sitting at tables of four. When inserting formulas in the spreadsheet, she applies the concepts of variable and functional relations to find the number of men and women as well as to calculate the total number of people in the restaurant (in the last column).

It is apparent that using the spreadsheet stressed the need to identify all the relevant variables and encouraged the search of functional relations. In addition, it led to a strategy that allowed addressing 


\begin{tabular}{|c|c|c|c|c|c|c|c|c|c|c|}
\hline \multirow[b]{2}{*}{ Number of men } & of women & Total & $\begin{array}{l}\text { Num } \\
\text { out the }\end{array}$ & $\begin{array}{l}\text { mber of people } \\
\text { taking } \\
\text { e group of three }\end{array}$ & $\begin{array}{l}\text { Number of } \\
\text { tables of four }\end{array}$ & \multirow[b]{2}{*}{$\begin{array}{l}\text { ne de } \\
\text { homens }\end{array}$} & \multirow{3}{*}{$\begin{array}{l}n{ }^{n} \text { de } \\
\text { mulheres } \\
2\end{array}$} & \multirow[b]{2}{*}{ total } & \multirow[b]{2}{*}{$\begin{array}{l}\mathrm{n} 2 \text { de pessoas } 5 / \\
\text { contar com as } 3\end{array}$} & \multirow[b]{2}{*}{$\begin{array}{l}n \& \text { de } \\
\text { mesas de } 4\end{array}$} \\
\hline & homens & $\begin{array}{l}\mathrm{n} 2 \text { de } \\
\text { mulheres }\end{array}$ & total & $\begin{array}{l}\mathrm{n} 2 \text { de pessoas s/ } \\
\text { contar com as } 3\end{array}$ & $\begin{array}{l}\text { no de } \\
\text { mesas de } 4\end{array}$ & & & & & \\
\hline & 1 & 2 & 3 & 0 & 0 & 1 & & 3 & $=F 4-3$ & $=\mathrm{G} 4 / 4$ \\
\hline & 2 & 4 & 6 & 3 & 0,75 & 2 & 4 & 6 & $=F 5-3$ & $=G 5 / 4$ \\
\hline & 3 & 6 & 9 & 6 & 1,5 & 3 & 6 & 9 & $=F 6-3$ & $=G 6 / 4$ \\
\hline & 4 & 8 & 12 & 9 & 2,25 & 4 & 8 & 12 & $=F 7-3$ & $=G 7 / 4$ \\
\hline & 5 & 10 & 15 & 12 & 3 & 5 & 10 & 15 & $=F 8-3$ & $=\mathrm{G} 8 / 4$ \\
\hline & 6 & 12 & 18 & 15 & 3,75 & 6 & 12 & 18 & $=F 9-3$ & $=69 / 4$ \\
\hline & 25 & 50 & 75 & 72 & 18 & 25 & 50 & 75 & $=F 28-3$ & $=\mathrm{G} 28 / 4$ \\
\hline & 26 & 52 & 78 & 75 & 18,75 & 26 & 52 & 78 & $=F 29.3$ & $=G 29 / 4$ \\
\hline & 27 & 54 & 81 & 78 & 19,5 & 27 & 54 & 81 & $=F 30-3$ & $=G 30 / 4$ \\
\hline & 28 & 56 & 84 & 81 & 20,25 & 28 & 56 & 84 & $=F 31-3$ & $=\mathrm{G} 31 / 4$ \\
\hline & 29 & 58 & 87 & 84 & 21 & 29 & 58 & 87 & $=F 32-3$ & $=G 32 / 4$ \\
\hline & 30 & 60 & 90 & 87 & 21,75 & 30 & 60 & 90 & $=F 33-3$ & $=\mathrm{G} 33 / 4$ \\
\hline & 31 & 62 & 93 & 90 & 22,5 & 31 & 62 & 93 & $=F 34-3$ & $=\mathrm{G} 34 / 4$ \\
\hline & 32 & 64 & 96 & 93 & 23,25 & 32 & 64 & 96 & $=F 35-3$ & $=G 35 / 4$ \\
\hline & 33 & 66 & 99 & 96 & 24 & 33 & 66 & 99 & $=F 36-3$ & $=\mathrm{G} 36 / 4$ \\
\hline
\end{tabular}

FIG. 4. Print-screen of Anne's representation. This figure appears in colour in the online version of Teaching Mathematics and its Applications.

the two conditions involved in the problem separately, and later making their connection by finding equal outcomes in both analyses.

Anne took a different approach from that of her colleagues (Fig. 4).

This student began by considering the condition that relates the number of men and the number of women and after obtained the total number of people.

The student concluded that the totals were multiples of 3 . Then she subtracted 3 people to the total of persons and divided the result by 4 . In cell $\mathrm{H} 3$, the student entered the title 'Number of tables of 4' and in the line bellow, the formula '= G4 /4' and then dragged the handle of the cell.

In her answer, Anne wrote: 'The maximum number was 87 for it was before the 4 friends came, if I considered the 99 and added the 4 friends I would get 103 but the capacity of the restaurant is 100 people, which means it is not the solution.'

We can see how Anne expressed the conditions in the spreadsheet and how they were chained in a particular sequence without separating them as in the previous examples.

These solutions show the importance of the identifications of all the variables and conditions in the problem. The work with the spreadsheet enables to validate the equivalence of expressions and experimentally to determine the solutions of simultaneous equations. In the three cases presented there is a clear image of how it is possible to generate different equivalent equations that translate the given problem. This is a fundamental concept that can be grasped with the use of the spreadsheet and that can be developed in subsequent symbolic approaches. Different equations may represent the same problem and this means a fundamental path to engage students in realizing how they can be transformed into others and to uncover instances of algebraic transformations in a set of conditions.

\section{Concluding remarks}

In any of the solutions presented the students identified the conditions and expressed them in the specific language of the spreadsheet. They have recognized the relevant variables and through the definition of columns expressed the relationships between these variables. Furthermore, it is possible 
to observe the correlation that exists between each of these conditions expressed numerically in the spreadsheet with the conditions of the system of equations shown in Fig. 1.

We found that the spreadsheet helped the students to establish relations between variables, expressed through numerical sequences and with the use of formulas to produce variable-columns. We claim that algebraic thinking was fostered by the affordances of the spreadsheet in generating the rules imposed by the problem. This result resonates with other research reports such as Ainley et al. (2004) but it also highlights the structure of students' algebraic thinking expressed in a particular representation system. It provided a clear indicator of how students interpreted the problem in light of their mathematical knowledge and their knowledge of the tool. The analysis allows us to make inferences about what is gained in using the spreadsheet to solve algebraic problems, and helps to understand the relationship between the symbolic language of the spreadsheet and the algebraic language. The use of the computational tool can be seen as a means to fill the gap between the algebraic thinking and the ability to use algebraic notation to express such thinking. The lack of algebraic notation and formal algebra methods does not mean the absence of algebraic thinking. The kind of algebraic thinking that emerges from the use of the spreadsheet is the kind that belongs to global algebraic activities (Kieran, 2004). Our perspective of algebraic thinking stresses the distinction between algebraic notation and algebraic structures, separated by a gap that is often underestimated. We suggest that this gap can be gainfully filled with suitable spreadsheet activities.

Rather than insisting on any particular symbolic notation, this gap should be accepted and used as a venue for students to practice their algebraic thinking. They should have the opportunity to engage in situations that promote such thinking without the constraints of formal symbolism (Zazkis \& Liljedhal, 2002).

The use of the spreadsheet in problem solving provides the establishment of connections between arithmetic and algebra. It strengthens the understanding of the functional relations involved, and the way they combine. The spreadsheet is an educational option to help students in the transition from arithmetic to algebra by making these two fields cohabiting.

\section{Acknowledgements}

This research is part of the Project PROBLEM@WEB (Mathematical Problem Solving: Views on an interactive web-based competition) that is being developed under the support of FCT - Fundação para a Ciência e Tecnologia, Grant n PTDC/CPE-CED/101635/2008.

\section{REFERENCES}

Ainley, J., Bills, L. \& Wilson, K. (2004) Construting meanings and utilities within algebraic tasks. Proceedings of the 28th conference of the international Group for the Psychology of Mathematics Education (M.J. Høines \& A. B. Fuglestad eds), vol. 2. Bergen, Norway: PME, pp. 1-8.

CARreira, S. (1992) A aprendizagem da trigonometria num contexto de aplicações e modelação com recurso à folha de cÁlculo (Master Dissertation). Lisboa: APM.

Dettori, G., Garuti, R. \& Lemut, E. (2001) From arithmetic to algebraic thinking by using a spreadsheet. Perspectives on school algebra (R. Sutherland, T. Rojano, A. Bell \& R. Linz eds). Dordrecht: Kluwer, pp. 191-208.

Haspekian, M. (2005) An 'instrumental approach' to study the integration of a computer tool into mathematics teaching: the case of spreadsheets. Int. J. Comput. Math. Learn., 10, 109-141. 
KIERAN, C. (1996) The changing face of school algebra. International Congress on Mathematical Education 8: Selected lectures (C. Alsina, J. M. Alvares, B. Hodgson, C. Laborde \& A. Pérez eds). Seville: SAEM Thales, pp. 271-290.

KIERAN, C. (2004) The core of algebra: reflections on its main activities. The Future of Teaching and Learning of Algebra: The 12th ICMI Study (K. Stacey et al. eds). Dordrecht: Kluwer Academic Publishers, pp. 21-34.

KIERAN, C. (2007) Developing algebraic reasoning: the role of sequenced tasks and teacher questions from the primary to the early secondary school levels. Quadrante, 16, 5-26.

OzGun-KocA, S. A. (2000) Using spreadsheets in mathematics education. Office of Educational Research and Improvement (ED). (Retrieved from http://www.ericdigests.org/2003-1/math.htm) [accessed 1 March 2011].

RADFORD, L. (2000) Signs and meanings in students' emergent algebraic thinking: a semiotic analysis. Educ. Stud. Math., 42, 237-268.

RoJAno, T. (2002) Mathematics learning in the junior secondary school: students' access to significant mathematical ideas. Handbook of international research in mathematics education (L. English, M. B. Bussi, G. A. Jones, R. A. Lesh \& D. Tirosh eds), vol. 1. Mahwah, NJ: Lawrence Erlbaum, pp. 143-161.

TABACh, M., Hershkowitz, R. \& ARCAVI, A. (2008) Learning beginning algebra with spreadsheets in a computer intensive environment. J. Math. Behav., 27, 48-63.

Weigand, H. \& Weller, H. (2001) Changes in working styles in a computer algebra environment: the case of functions. International Journal of Computers in Mathematical Learning, 6, 87-111.

Zazkis, R. \& Liljedhal, P. (2002) Generalization of patterns: the tension between algebraic thinking and algebraic notation. Educ. Stud. Math., 49, 379-402.

Sandra Nobre is a middle school mathematics teacher at the Escola Básica 2,3 Professor Paula Nogueira. She has collaborated in the national mathematics teacher training programme within the current Portuguese reform in the mathematics curriculum for elementary and middle schools. She is developing her doctorate research in mathematics education at the Institute of Education of the University of Lisbon. Her research domain is students' development of algebraic thinking through the use of the spreadsheet in problemsolving tasks.

Nélia Amado is assistant professor of mathematics education and mathematics in the Mathematics Department of the Faculty of Sciences and Technology, University of Algarve. She is currently teaching in pre-service teacher education and postgraduate studies in mathematics education. She is a researcher at the Research Unit of the Institute of Education, University of Lisbon. Her research work involves teachers' professional practice, including the use of technology in classroom, formative assessment in mathematics teaching and learning, and problem solving, in both school curriculum and beyond-school contexts. She is a member of the Problem@Web Project, which aims to understand students' problemsolving activity in a web-based regional mathematical competition. She is also a member of the national committee that supports current Portuguese reform in the mathematics curriculum for elementary and middle schools.

Susana Carreira is associate professor of mathematics education and mathematics in the Mathematics Department of the Faculty of Sciences and Technology, University of Algarve and an invited associate professor of mathematics education at the Institute of Education, University of Lisbon. She is currently teaching in pre-service teacher education and postgraduate studies in mathematics education. She is a researcher at the Research Unit of the Institute of Education, University of Lisbon. Her research work includes mathematical modelling in school mathematics, teaching and learning mathematics with ICT tools, 
namely the use of the spreadsheet for mathematical explorations, and problem solving as a context for developing mathematical thinking and creativity. She is currently the coordinator of the Problem@Web Project, which aims to understand students' problem-solving activity in a web-based regional mathematical competition. 